\title{
A UNIVERSIDADE LATINO-AMERICANA DO FUTURO QUE SUA SOCIEDADE ESTÁ CONSTRUINDO'
}

\begin{tabular}{c}
\hline THE LATIN AMERICAN UNIVERSITY OF THE \\
FUTURE THAT YOUR COMPANY IS BUILDING \\
\hline LA UNIVERSIDAD LATINOAMERICANA DEL \\
FUTURO QUE SU SOCIEDAD ESTÁ CONSTRUYENDO \\
\hline
\end{tabular}

Renato Dagnino ${ }^{2}$

\begin{abstract}
RESUMO
A concepção de um novo projeto para a universidade brasileira, neste momento em ela vem se expandindo e mantendo um estilo pouco aderente ao cenário da democratização em curso e às restrições e oportunidades colocadas pelos contextos nacional e mundial, é tarefa urgente do segmento de esquerda da comunidade universitária. Contrapondo-se à síndrome do produtivismo-cientificismo-inovacionismo, e privilegiando o canal da Extensão que pode vir a diminuir sua disfuncionalidade e insulamento, revisitando o anátema da qualidade versus relevância, e provocando uma alteração na sua agenda de Pesquisa e Ensino, o argumento proposto tem como eixo o questionamento da concepção dogmática da Neutralidade e do Determinismo da tecnociência ainda predominante naquele segmento. Reconhecendo a necessidade de disputar a hegemonia com os que defendem uma política de alianças com o setor empresarial, cada vez mais "financeirizado", desnacionalizado, desindustrializado, mimético e ambientalmente irresponsável, se sugere uma aproximação com a Economia Solidária e seus empreendimentos. A Adequação Sociotécnica e o desenvolvimento de Tecnologia Social passariam a ser um vetor da práxis universitária (re)unindo "inexatos" e "desumanos" em torno de um projeto orientado à construção de uma sociedade inclusiva.
\end{abstract}

PALAVRAS-CHAVE: Projeto para a universidade. Neutralidade e determinismo da tecnociência. Economia solidária. Tecnologia social

\begin{abstract}
The design of a new project for the Brazilian university, this time it is expanding keeping a little sticky style to the ongoing democratization of the scenario and the constraints and opportunities posed by national and global contexts, is an urgent task of the community left segment university. Opposed to the productivism-scientisminovacionismo syndrome, and favoring the extension of the channel that may ultimately decrease its dysfunctionality and insularity, revisit the anathema of quality versus relevance, and cause a change in your schedule for Research and Education, the argument proposed has the axis questioning the dogmatic conception of neutrality and Determinism of the still predominant technoscience that segment. Recognizing the need to compete for hegemony with those who advocate a policy of alliances with the business sector, increasingly "financerizado" denationalized, desindustrializado, mimetic and environmentally irresponsible, it is suggested
\end{abstract}

\footnotetext{
${ }^{1}$ A origem deste trabalho é um "position paper" solicitado pelos organizadores do Fórum Latino-americano de Educação Superior realizado em 17 e 18 de novembro de 2014 em Foz do Iguaçu (a quem agradeço a honra que me concederam) e apresentado no "Painel 2 - Sociedade do Conhecimento e Educação Superior". Posteriormente, ele resultou numa versão adaptada, sintetizada e traduzida ao espanhol que foi publicada na Argentina. Seu título original, e por isso o conteúdo de sua introdução, foi modificado para um mais coerente com seu conteúdo. Por sugestão desta revista essa versão foi traduzido ao português por Hildegard Susana Jung (Mestre em Educação, URI; Doutoranda em Educação, Unilasalle) a quem agradeço.

${ }^{2}$ Docente da Universidade Estadual de Campinas. Campinas - SP - Brasil. E-mail: rdagnino@ige.unicamp.br Submetido em: 10/01/2016 - Aceito em: 26/04/2016
} 
an approach to the Solidarity Economy and its developments. The Sociotechnical Adequacy and the development of social technology would become a vector of university practice (re) joining "inaccurate" and "inhuman" around a project aimed at building an inclusive society.

KEYWORDS: Design for the university. Neutrality and determinism of technoscience. Solidarity economy. Social technology

\section{RESUMEN}

La concepción de un nuevo proyecto para la universidad brasileña, en este momento que ella se expande manteniendo un estilo poco adherente al escenario de la democratización en curso y a las restricciones y oportunidades puestas por los contextos nacional y mundial, es tarea urgente del segmento de izquierda de la comunidad universitaria. Contraponiéndose al síndrome del productivismo-cientificismo-innovacionismo, y privilegiando el canal de la Extensión que puede venir a disminuir su disfuncionalidad y aislamiento, revisitar el anatema de la calidad versus relevancia, y provocar una alteración en su agenda de Investigación y Enseñanza, el argumento propuesto tiene como eje el cuestionamiento de la concepción dogmática de la Neutralidad y del Determinismo de la tecnociencia todavía predominante en aquel segmento. Reconociendo la necesidad de disputar la hegemonía con los que defienden una política de alianzas con el sector empresarial, cada vez más "financierizado", desnacionalizado, desindustrializado, mimético y ambientalmente irresponsable, se sugiere una aproximación con la Economía Solidaria y sus emprendimientos. La Adecuación Sociotécnica y el desarrollo de Tecnología Social pasarían a ser un vector de la praxis universitaria (re)uniendo "inexactos" y "deshumanos" alrededor de un proyecto orientado a la construcción de una sociedad inclusiva.

PALABRAS-CLAVE: Proyecto para la universidad. Neutralidad y determinismo de la tecnociencia. Economía solidaria. Tecnología social

\section{Introdução}

Inicio $^{3}$ esta introdução explicando por que esta contribuição para o debate intitulada "Sociedade do Conhecimento e Educação Superior" não terá este conceito - Sociedade do Conhecimento-, tal como é usualmente entendido, como seu centro de análise.

Pode-se rastrear a origem deste conceito em um trabalho de Solow publicado em 1957 e intitulado Cambio Tecnológico y la Función de Producción Agregada. Ali, ele observa que a metade do crescimento econômico dos EUA não podia ser atribuída ao aumento das duas variáveis (capital e trabalho) com as quais os economistas neoclássicos explicavam o crescimento do PIB. Esta diferença, atribuída ao conhecimento que estava sendo incorporado à produção econômica e que não era medida na função de produção neoclássica, passou a ser chamada de "Resíduo de Solow" e graças a este descobrimento (ou, como indico abaixo, redescobrimento) recebeu o prêmio Nobel de Economia.

Em 1962, outro economista -Fritz Machlup- utilizou pela primeira vez, referindo-se à sociedade norte-americana, o termo "Economia do Conhecimento", buscando "demonstrar" que o desenvolvimento era cada vez mais um resultado da acumulação e utilização do

\footnotetext{
${ }^{3}$ Escrevo em primeira pessoa do singular, em um tom de "magister dixit" que pode parecer pretencioso e sem referir-me aos que inspiraram as ideias polêmicas que aqui exponho, para reforçar o caráter de insumo para uma discussão substantiva que quer provocar este documento. Isto não quer dizer que não possa, muito pelo contrário, espero que consiga, inspirar algo coletivo.
}

(C) Rev. Inter. Educ. Sup. $\quad$ Campinas, SP

\begin{tabular}{|l|l|l|l|l}
2 & n.1 & p.31-50 & jan./abr. 2016 & ISSN 2446-9424
\end{tabular}


conhecimento. Ao estimar sua contribuição para o crescimento econômico, fortaleceu a opinião de Solow: o "resíduo" foi equivalente, em 1958, a 29\% do PIB norte-americano.

A partir desse momento, autores de diversas disciplinas começaram a prestar atenção ao que passou a ser conhecido como a Economia ou a Sociedade do Conhecimento e, também, como a Economia ou a Sociedade da Informação.

Ainda que a descoberta que originou o conceito seja provinda da Economia Neoclássica, o pensamento marxista, antes disso, já havia evidenciado sua importância. $\mathrm{O}$ fato de que, ao contrário do que faria a interpretação neoclássica, Marx não concebia a produção econômica separando o "capital" do "trabalho" para em seguida somar ao modelo o conhecimento tecnocientífico -como fizeram os adeptos da Economia da Inovação inspirados em Schumpeter- fazia com que não tivesse sentido para um marxista tentar quantificar sua "contribuição" para o crescimento econômico.

Era tanta a importância conferida por Marx ao elemento conhecimento (tecnocientífico) que, associando-o à "força de trabalho" e aos "meios de produção", ele os denominou "forças produtivas", colocando-as com um papel central em sua explicação sobre o funcionamento da economia. Seria a introdução de conhecimento com o objetivo de aumentar a produtividade da força de trabalho por parte dos "proprietários dos meios de produção" no processo de trabalho controlado por eles - o que permitiria a extração da "maisvalia relativa"- o elemento dinamizador das forças produtivas. No capitalismo, por estar a serviço da "acumulação do capital", as forças produtivas (ou a tecnociência, em uma linguagem mais atual) seriam fundamentais para sua manutenção e expansão. E, também, ao conferir-lhe um caráter progressivo - de positividade intrínseca associada ao valor do conhecimento-, assegurar, legitimando e naturalizando sua hegemonia.

$\mathrm{O}$ argumento apresentado até aqui é para mim suficiente para explicar porque o conceito de Sociedade do Conhecimento não é apropriado para que em um país periférico, com as características e diferenças com relação aos países capitalistas avançados, se busque refletir sobre o rumo da Educação Superior como alicerce para a construção de um cenário desejável de maior equidade, justiça e sustentabilidade ambiental.

Particularmente, porque está cada vez mais explícita a inadequação desse "conhecimento", que deriva de uma dinâmica tecnocientífica monopolizada por esses países e da "sociedade" a ela acoplada e cada vez mais caracterizada pela obsolescência programada, o consumismo exacerbado, a degradação ambiental e a inequidade crescente, para orientar a discussão que proponho.

Mas existe outra razão para meu argumento. Ela se refere à percepção bastante comum entre estudiosos destes temas de que esse "conhecimento", ao ser apropriado por outros atores e colocado a serviço de outro projeto político, poderia apoiar a construção desse cenário. Boa parte destes estudiosos aceita a interpretação marxista que apresentei até aqui 
a eles me dirijo para argumentar que não é plausível a ideia de que esse "conhecimento" possa desempenhar esse papel.

$\mathrm{O}$ argumento daqueles que sustentam isto, fica bem ilustrado na frase de Marx -que se tornou tristemente célebre - que sustenta que "o moinho a braço vos dará a sociedade com o suserano; o moinho a vapor, a sociedade com o capitalismo industrial”, e que levou Lenin e também marxistas tão dispares como Stalin e Trotsky a acreditarem na ideia de que o avanço contínuo e inexorável das forças produtivas seria a fora motriz da história. Que elas, ciclicamente, quando as "relações técnicas e sociais de produção" as pressionassem, chegariam a sucessivos e mais avançados "modos de produção".

Marcada pelo viés otimista da neutralidade e o determinismo da tecnociência, essa interpretação procurava explicar movimentos extensos e complexos que originavam a transição entre os "modos de produção": escravista, feudal, capitalista, socialista, comunista. Isto não implicava que os marxistas deixassem de denunciar o fato de que, no curto prazo e dentro do estádio capitalista, atuando a serviço do capital, as forças produtivas (ou o conhecimento tecnocientífico) prejudicavam a classe trabalhadora e o conjunto da sociedade. Mas seria essa mesma tecnociência que então "servia ao capital" e "oprimia a classe operária" a qual, "apropriada por ela" depois da "revolução", a "libertaria" e permitiria que os trabalhadores construíssem o ideal do "socialismo".

A maioria dos marxistas, inclusive aqueles que se dedicam a temas relacionados com as políticas cognitivas (de Ensino e Ciência e Tecnologia), aceita esta interpretação. E isso apesar de que em muitos outros trechos de sua obra, Marx tenha sugerido exatamente o contrário e de que existam interpretações de marxistas contemporâneos que não somente a questionam, mas que a consideram uma das causas da degeneração burocrática do socialismo real.

O resultado deste questionamento reforça a não aceitação da expressão "Sociedade do Conhecimento" como foco para tratar o tema da educação superior. Isto porque, sem que seja formulada a pergunta acerca de que conhecimento se trata, se estará sempre implicitamente assumindo que é aquele conhecimento, o qual foi caracterizado como inadequado, que está sendo tomado como referência.

Neste sentido, as ideais que vou tratar aqui, sem negar muitas das contribuições feitas sobre o tema, e que omito (como já assinalei) em favor da brevidade, partem de um questionamento da proposição atualmente hegemônica de que vivemos em uma economia ou sociedade fundada no conhecimento, que seria a base para muitas, ou talvez para todas as decisões humanas e um ativo essencial para indivíduos e organizações de qualquer natureza. Questionamento que deriva da indagação acerca de sobre qual conhecimento se fala e da constatação de que não é pretensamente neutro e universal o conhecimento que impregna o conceito de Sociedade do Conhecimento aquele que deve sustentar a sociedade inclusiva que queremos. A qual, como argumentarei, terá que ser duplamente intensiva em conhecimento. 
Primeiro, porque a tecnociência que essa sociedade demanda, que vai desde o "saber popular" até a ultra high tech, envolve procedimentos (de ensino, pesquisa e extensão, somente para ficar no terreno universitário) originais, transdisciplinares e de alta intensidade cognitiva. Segundo, porque pela característica inegociável de inclusividade dessa sociedade, esse conhecimento terá que ser de todos e desenvolvido com procedimentos que precisam ser concebidos, também, por todos.

\section{Diagnosticando o estilo da universidade vigente}

Inicialmente, sintetizo o diagnóstico que faço sobre a universidade pública no Brasil ${ }^{4}$ em torno do qual pretendo desenvolver meu argumento para provocar a discussão e que resumo em uma palavra: disfuncionalidade. A universidade não é funcional; ou seja, não é necessária, nem à classe dominante, nem à classe dominada.

Esta disfuncionalidade que caracteriza o estilo que a universidade pública apresenta hoje é diagnosticada de modo diferente pela direita e pela esquerda. Por isso, são diferentes as propostas sobre o tipo de aliança que ela deve buscar para ganhar forças, recuperar sua legitimidade e superar a disfuncionalidade e, em consequência, o projeto de universidade que se busque alcançar.

\subsection{Estilo, modelo e projeto}

Antes de avançar com os diagnósticos, é conveniente uma digressão que explicite a diferença entre o que chamo de estilo, modelo e projeto.

A noção de estilo se refere à maneira como, em um dado momento, uma organização funciona. É o resultado dos interesses das elites de contar com uma organização que permita exercer e consolidar seu poder em um determinado contexto e da necessidade de adaptá-lo a eventuais mudanças. Neste sentido, dou um exemplo próximo aos temas deste documento. Na Europa, o nascimento e a consolidação da organização universidade tal como atualmente a conhecemos se desdobra para atender às demandas cognitivas do capitalismo em expansão. No Brasil e também na maioria dos países latino-americanos, nossas primeiras Escolas Direito, Medicina, Engenharia de Minas, etc. - respondiam também aos óbvios interesses da elite.

Um estilo vai se estabelecendo à medida que são realizados, de forma incrementada, os ajustes para adaptar as organizações às conjunturas estabelecidas pelo contexto. Outro exemplo: acompanhando mimeticamente, por um lado, a tendência à expansão da universidade nos países avançados, a universidade latino-americana foi criando seu estilo.

\footnotetext{
${ }^{4}$ Guardadas as proporções, algo do que apresento neste documento pode ser válido para descrever, explicar e, quem sabe, prescrever a esfera que transcende à universidade pública e abarca o planejamento da educação superior em seu conjunto. E, também com os caveats conhecidos, para orientar procedimentos semelhantes em outros países latino-americanos.
}

(C) Rev. Inter. Educ. Sup.

Campinas, SP

p. $31-50$

jan./abr. 2016

ISSN 2446-9424 
Por outro lado, o caráter periférico de nosso processo de desenvolvimento, inicialmente marcado por um viés primário exportador e posteriormente pela industrialização por substituição de importações, contribuiu para que esse estilo não fosse estritamente funcional, em termos econômicos, aos interesses das elites. De nenhuma forma foi demandado conhecimento localmente produzido, em especial aquele incorporado em pessoal qualificado, que nos países avançados é recrutado pelas empresas para realizar a pesquisa que assegura sua competitividade. O estilo de nossa universidade pública é o resultado de um processo incremental de tomada de decisão ocorrido no âmbito das elites que, em função da enorme concentração de poder econômico e político que nos caracteriza, não teve praticamente nenhuma participação das classes subalternas.

Quando um estilo se consolida e é considerado exitoso por um ator em algum aspecto dominante, passa a ser visto como um modelo a ser emulado. De novo, e somente para esclarecer a ideia, me refiro à maneira como se originaram os denominados modelos de universidade: alemã (Humboldt: conhecimento para a produção), francesa (napoleônica: interesses do Estado), inglesa (pesquisa para o "avanço do conhecimento") e, mais recentemente, a estadunidense.

Um projeto - ao contrário do estilo, que é algo que vai se conformando incrementalmente e pode se transformar em um modelo - é uma proposta concebida racionalmente em função da ação de um ator que possui algum nível de insatisfação com o estilo vigente. O projeto é formulado para se contrapor e mudar um determinado estilo de funcionamento da organização.

Como exemplo para ilustrar a noção de projeto, pode-se referir, na América Latina, aos resultados do movimento estudantil de Córdoba na segunda década do século passado, ao projeto da universidade de Brasília no início dos anos 1960 e ao projeto da ditadura militar implementado ao final da década de 1960 por influência do acordo MEC (Ministério da Educação) com a USAID (United States Agency for International Development). Como se sabe, o primeiro projeto foi formulado buscando implementar uma reforma da universidade proposta por segmentos progressistas da sociedade. O segundo, foi concebido para alterar o estilo livresco da universidade baseada nas cátedras, no âmbito de um processo mais abrangente conhecido como "reformas de base". O terceiro, derivado da concepção de universidade do governo militar, surgiu como uma reação ao modelo anterior, que havia adquirido um apoio institucional que poderia ter transformado o estilo da universidade e que era defendido pelo movimento estudantil.

Como consequência de seu caráter proativo, um projeto, para ser implementado, requer uma estratégia de formulação que envolva, inclusive, uma avaliação do poder dos atores favoráveis e contrários, táticas de acumulação de forças e de implementação. Ou seja, um conjunto de mecanismos institucionais capazes de materializar as diretrizes responsáveis pela transformação do estilo ao qual o novo projeto se pretende contrapor. 
$\mathrm{Na}$ seção 4 tratarei especificamente do que me parece que é o projeto que devemos conceber para a universidade latino-americana, enquanto que o restante desta seção e a seção 3 se refere mais diretamente à noção de estilo e aos modelos que se pretendeu emular. De qualquer forma, o propósito do documento é apresentar elementos que permitam a concepção de um projeto para a universidade que atenda às demandas e apoie o processo de democratização política e económica em curso no país.

\subsection{O diagnóstico da direita}

A direita da universidade pública se dedica a encontrar aliados na esfera privada. A esquerda sabe que universidade pública não rima com empresa privada e sim com "o público". Sua busca por aliados deve estar cada vez mais orientada à esfera pública. São os movimentos sociais e o próprio Estado os atores que precisam do (e têm direito ao) conhecimento que a universidade pública pode produzir. A empresa privada até hoje não demandou de forma significativa o conhecimento localmente produzido. E, quando o fizer, poderá buscá-lo na universidade privada.

A direita brasileira vê a universidade pública como disfuncional ao modelo neoliberal que procurou implementar desde o final dos anos 1980. Um modelo de abertura econômica indiscriminada, de desindustrialização, que não precisa de uma universidade que faça pesquisa e forme recursos humanos qualificados. Este diagnóstico de disfuncionalidade tem como ação política uma visão pragmática da universidade e o consequente corte de tudo o que se considera "desnecessário", que se manifesta não somente na pressão sobre os salários e as condições de trabalho, mas também na mudança da função e reconhecimento que hoje a universidade já não tem perante as elites políticas e perante o poder econômico no Brasil.

Durante muito tempo a comunidade universitária conseguiu relacionar-se com o poder econômico e político, permitindo que a universidade existisse da forma que o Brasil tem feito até agora. O próprio governo militar viu na universidade pública um instrumento para seu projeto de Brasil "grande potência" e estimulou várias áreas do conhecimento, sobretudo as áreas duras. Essa vinculação hoje se torna impossível.

Esta situação de crise, de disfuncionalidade, pode ser resumida mais ou menos desta forma: a universidade não é mais necessária para que a classe dominante siga com seu projeto de acumulação; a universidade, em um país cada vez mais dependente do ponto de vista tecnocientífico, é muito cara para ser desnecessária. Seu alto custo e baixa legitimidade a tornam cada vez mais indefesa perante as ameaças de privatização.

\subsection{O diagnóstico da esquerda}

A universidade pública no Brasil foi responsável, até os anos 1960, pela maior parte das matrículas da educação superior. Antes do golpe militar de 1964, a universidade pública era responsável por entre 60 e 70\% das matrículas e hoje está entre os 20 e 30\%. Esse número

n.1 1 p.31-50


varia. É maior nos estados do noroeste, onde as elites - diferentemente do que nos estados mais ricos - conseguiram pressionar para que se estabelecessem universidades federais.

Por outro lado, do total de jovens brasileiros entre 18 e 24 anos, somente $15 \%$ está no terceiro nível educativo, o que quer dizer que apenas 3 a $4 \%$ desses jovens recebem das universidades públicas uma educação que pode ser considerada de qualidade.

É frequente a crítica de que os jovens que entram na universidade pública passando na prova do vestibular tendem a ser os que cursaram seus estudos primários e secundários no setor privado, que desde a época da ditadura militar é considerado de melhor nível que o setor público. Daí que as pessoas com menos recursos estão nas universidades privadas e os ricos vão à universidade pública.

Esta situação faz com que também exista um diagnóstico da esquerda acerca da disfuncionalidade. Para ela, a universidade pública não representa, como chegou a ser no passado, uma alternativa ou possibilidade de ascensão social para as classes de baixos recursos.

Durante a vigência do modelo por substituição de importações, existia a possibilidade, ou a meta, de que o Brasil, como outros países latino-americanos, depois de substituir importações, pudesse também substituir o conhecimento tecnocientífico (a ingenuamente denominada "tecnologia nacional") necessário para produzir esses bens. O abandono desse modelo, que se manifestou na abertura comercial imposta pela globalização e aceita pela elite neoliberal, inviabilizou essa meta. As atividades de pesquisa, tanto a adaptativa - realizada nos institutos públicos da área industrial que pretendiam situar-se entre a universidade e a empresa nacional -, como a universitária -concebida em torno de uma agenda que imita o que fizeram os pares do exterior-, que apoiariam com dois prazos de maduração distintos o projeto de autonomia tecnológica sustentado pelos militares, se tornaram desnecessárias.

Enfim, poderíamos dizer que hoje a universidade pública não é funcional, não é necessária, nem para a classe dominante, nem para a classe dominada.

\section{Condicionantes do estilo vigente}

No que segue, minha intenção é caracterizar os atores presentes no espaço da policy e da politics da política cognitiva (hoje constituído, basicamente, pelas políticas de C\&T e de educação superior, mas que no futuro se espera que seja um núcleo de algo mais abrangente) e apresentar um diagnóstico já avançado para a análise de três aspectos do contexto socioeconómico que são centrais para a concepção de um novo projeto. Para facilitar a abordagem descritiva, adoto a tradicional trilogia Ensino, Pesquisa e Extensão, que é aludida, por sua vez, a partir de una postura prescritiva ou normativa dentro da seção "Elementos para a concepção de um novo projeto". 
Durante o governo militar, a universidade desenvolveu uma estratégia defensiva para preservar-se do adverso contexto político. Para isso, a universidade arriou a incômoda bandeira da relevância que o projeto da Universidade de Brasília (Darcy Ribeiro, Paulo Freire, etc.) havia levantado e, para manter o espaço crítico que a universidade pública proporcionava, hasteou a da "qualidade". A bandeira da qualidade implicou na adoção de critérios acadêmicos de contratação e promoção que mantiveram a universidade a salvo do autoritarismo e oportunismo dos regimes militares.

Entretanto, escondendo-se defensivamente atrás dos biombos da "ciência pura", a esquerda universitária parece ter se separado da responsabilidade de gerar conhecimento relevante para sua sociedade.

\subsection{Aspectos relativos à função Pesquisa}

Começo pela função Pesquisa, alterando a ordem em que elas são usualmente mencionadas, não por considerá-la mais importante, mas porque foi a dinâmica que ela assumiu nas universidades públicas nas últimas duas décadas que orientou as outras duas funções.

O ambiente de valorização da pesquisa (em detrimento, inclusive, do ensino) e a associada estrutura material e imaterial (ideológica, por exemplo) existentes não permitiram nem permitem atualmente uma mudança de orientação das atividades de pesquisa.

Como em outras ocasiões em que a sociedade lhe exigiu um protagonismo inédito, na conjuntura atual a comunidade de pesquisa atuou como se sua ação, por ser a mais "correta", pudesse modificar (na linha do que apregoa o "modelo institucional ofertista linear" que a coloca como o gatilho de um círculo virtuoso) o comportamento dos atores governamentais, empresariais, entre outros, presentes no contexto em que se insere o complexo público de ensino e pesquisa, e os arranjos institucionais de planejamento.

Se durante a ditadura militar a universidade se protegeu de um contexto adverso pela via meritocrática e corporativa, no período de democratização posterior não foi capaz de evitar que este comportamento tático, de defesa, se transformasse em uma conduta permanente. Não fomos capazes de hastear a bandeira da relevância que a democratização do país exigia (e cada vez exige mais). Nem de tecer endógena e autonomamente uma bandeira de qualidade que possui, como ocorre nos países desenvolvidos, entretecidos os fios da relevância.

Pelo contrário, não somente mantivemos hasteada a bandeira da qualidade mimética, mas também hasteamos outras, adventícias, que mostram a nossos pares do norte que estamos à altura do que eles nos convenceram que é a tecnociência de "qualidade". Essas bandeiras de sinalização - do cientificismo, do produtivismo e do inovacionismo - estão servindo para 
guiar as políticas de educação e de C\&T de nosso governo, de modo pouco coerente com sua orientação popular e democrática, renunciando à elaboração de uma política cognitiva que sirva para construir a plataforma cognitiva de lançamento da sociedade que queremos.

As "ciências duras", que foram as primeiras que se institucionalizaram - e por isso ditam as normas de "qualidade" -, compreensivelmente o fizeram à imagem e semelhança daquilo que existia onde seus praticantes foram doutorar-se. Para eles, é mais difícil aceitar que se poderia fazer outro tipo de pesquisa e que poderíamos explorar a fronteira do conhecimento tecnocientífico de outra forma.

Como se sabe, um tema central nesta discussão é como avaliar o que se faz na universidade. Mesmo quando se aceita a necessidade de alterar a forma de avaliação universitária e científica, a discussão que fica no terreno do conflito é como se define a qualidade. Nos países desenvolvidos, a sociedade emite sinais de relevância que indicam o que é relevante. Esses sinais são recebidos pela comunidade científica de uma forma muito sutil, de uma forma que ela mesma não se dá conta de que a recebe. Entretanto, os campos de relevância delimitados por referidos sinais estão ali e o que fazem os cientistas é trabalhá-los com qualidade. E qualidade, neste caso, na ausência de algo melhor, é sempre o julgamento dos pares.

Novamente, quando falo de relevância, não estou fazendo um juízo de valor. Os Estados Unidos, nos anos 1980, chegaram a gastar $70 \%$ dos recursos públicos para pesquisas na área militar. Somado ao gasto que ia para a energia nuclear e aeroespacial, chegava a $85 \%$. Os $15 \%$ restantes eram para agricultura, saúde, etc. Mas não havia nenhuma dúvida de que a população estadunidense (ou o establishment que a representava) nesse momento acreditava que isso era importante. Havia um sinal de relevância e os cientistas faziam com qualidade o que era considerado importante. Ou seja, nos países desenvolvidos a relevância é essencial, necessária e ex ante. A qualidade é suplementar, não é necessária e é ex post. A qualidade, portanto, não é universal: é socialmente construída. No nosso caso, que temos uma situação e uma condição periféricas, onde as empresas não fazem pesquisa e o Estado e os movimentos sociais não demandam conhecimento novo, não são emitidos fortes sinais de relevância.

$\mathrm{Na}$ atualidade, a universidade pública orienta seu ensino e sua pesquisa de modo exógeno. As agendas e os critérios de pesquisa são tentativas de emular o que se faz nas universidades de maior prestígio dos países desenvolvidos. Isto tem lugar como uma imitação do que se chama "dinâmica de exploração da fronteira mundial", mas que na realidade é um processo que produz um conhecimento cada vez mais monopolizado, que é visto como universal e neutro. Não há consciência entre nós de que poderia haver outro tipo de tecnociência e de pesquisa diferente daquela que é produzida por e para as empresas dos países desenvolvidos.

De fato, hoje, as 20 empresas que mais gastam em pesquisa no mundo investem mais que a França e a Grã Bretanha, dois países líderes em muitos campos do conhecimento, que 
junto com ouros seis gastam $90 \%$ daquilo que se investe no mundo em pesquisa. Essas 20 empresas fazem ciência básica ou ciência aplicada? Uma delas tem dez prêmios Nobel entre seus empregados. O que faz um prêmio Nobel em uma empresa? Ciência, tecnologia, ou tecnociência? O que quero dizer é que cada vez mais a pesquisa que nós ainda chamamos de "básica" se faz também na empresa e a aplicada na universidade.

Hoje, no mundo, $70 \%$ do total da pesquisa é executada em empresas, das quais $70 \%$ são multinacionais. Isto significa que a metade da pesquisa mundial é realizada em empresas multinacionais que, como sabemos, adoram o meio ambiente e adoram gerar emprego.

\subsection{Aspectos relativos à função Ensino}

$\mathrm{Na}$ função de Ensino se visualizam tendências endógenas recentes que alteram o quadro já apresentado de modo incremental, adaptando-se ao processo em curso de aprofundamento da democracia. Não há, entretanto, sinais que apontem para a gestação de um projeto que o altere de modo significativo.

Entre muitas outras referências, destaco que a atual coalisão que governa o Brasil aumentou, entre os anos de 2002 e 2014, em 58\% o número dos agentes públicos federais vinculados à educação (basicamente ensino superior), que passou de 165 a 260 mil profissionais. Esse crescimento se orientou à criação de 400 novas escolas de educação profissional, científica e tecnológica, triplicando o número de unidades existentes em 2002, e 18 novas universidades em 152 novos campos, duplicando a matrícula e os municípios com instituições federais.

O que tento seguir não é o aspecto quantitativo, mas o "qualitativo". Isto é, o relativo à orientação que está sendo dada à expansão do ensino, de uma forma geral, e da universidade pública, em particular. A orientação "para o trabalho" e de curto prazo poderá levar à obtenção de emprego, que é o que a maioria dos cursos profissionalizantes se propõe como resultado?

Outro ponto a aprofundar é o empreendedorismo e o que se veio a chamar de - por meio de um deslizamento semântico que possibilita o que os cientistas políticos denominam "confluência perversa" - o "empreendedorismo social". Associado ao eufemismo "responsabilidade social empresarial", este fenômeno surge devido à dificuldade de transformar os jovens das classes subalternas - marginalizados ou "excluídos" - em "incluídos" e os ingressa no setor formal de modo a permitir, é importante que se diga, a extração de mais-valia e a geração de lucro empresarial. Essa proposta, que atrai pessoas de esquerda porque o empreendedor individual não extrai mais-valia e o pequeno, teoricamente, explora pouco, supõe a existência de um mercado que compra o tipo de bens e serviços que eles seriam capazes de produzir. A informação disponível mostra a inviabilidade desta proposta. A porção de $1 \%$ dos mais ricos da população brasileira (cerca de 1,7 milhões de pessoas) se apropria de $13 \%$ do total das rendas: a mesma fração da qual se apropriam $50 \%$

\begin{tabular}{l|l} 
n.1 & p.31-50
\end{tabular}


dos mais pobres (algo em torno de 87 milhões de pessoas), o que significa que a metade de nossa população sobrevive com cerca de 5 dólares por dia.

Seguindo essa cadeia, é necessário comentar outra proposta frequentemente reproduzida, que é a de orientar a capacidade de produção desses jovens - agora qualificados - para o mercado externo. E há muitas razões para saber que, por essa via, nem crescimento teremos.

Para competir no mercado mundial de bens industriais de baixa e média intensidade tecnológica e produzidos com mão de obra barata - mantendo a ideia - força "exportar é que importa" -, teríamos que reduzir ainda mais o salário brasileiro. Ou, retomando algum tipo de proteção do mercado interno, criar um espaço interno a nossa economia para que a massa de operários qualificados por esse esforço de profissionalização dos jovens, que por isso seriam mais produtivos, aumentasse a competitividade das empresas - nacionais ou estrangeiras aqui localizadas.

Fechando o tratamento da questão "qualitativa" de curto prazo (que não questiona o caráter de educação "para o trabalho" que está seguindo o processo de expansão de ensino, coisa que será abordada na seção seguinte de modo normativo), sintetizo minha opinião. E faço isso destacando o fato de que a "janela da oportunidade" que esteve aberta até que se iniciou a década dos anos oitenta para que o país promovesse a formação tecnocientífica maciça de pessoal para a produção de bens e serviços, que o estilo nacionaldesenvolvimentista vigente demandava e a conjuntura internacional permitia encontra-se hoje fechada. E agregando que não há prospectiva plausível que aponte para sua reabertura. Isto significa que a formação tecnocientífica que temos que impulsionar deve levar em conta uma análise mais radical (etimologicamente: ir às raízes) da configuração atual do contexto de ensino e da atividade tecnocientífica, e do que ela implica em termos de restrições e oportunidades para o futuro, coisa que deixo para a próxima seção.

\subsection{Aspectos relativos à função Extensão}

Para situar a problemática da Extensão, começo afirmando que a pesquisa que fazemos na universidade é disciplinar - orientada por disciplinas - e não por problemas do contexto socioeconômico. E todos sabemos que os problemas "são" multidisciplinares. Mesmo assim, na universidade seguimos compartimentados em departamentos. Nosso modo de ensinar e de pesquisar não está orientado a tratar problemas de maneira interdisciplinar e é disfuncionalmente "disciplinado".

Nossa pesquisa é auto-referenciada: não perguntamos a ninguém o que devemos pesquisar. Como temos um quase "monopólio" da capacidade de pesquisar, acreditamos que cabe exclusivamente a nós mesmos definir a agenda de pesquisa. Mas nossa agenda de pesquisa é definida, de fato, pelos países centrais; nós apenas adotamos como nossa a que eles concebem a partir de suas realidades, dos sinais de relevância emitidos por seus

\begin{tabular}{l|l|l|l|l|l|l} 
(C) Rev. Inter. Educ. Sup. & Campinas, SP & v.2 & n.1 & p.31-50 & jan./abr. 2016 & ISSN 2446-9424
\end{tabular}


respectivos "tecidos sociais". É cientificista, na medida em que acredita que a ciência é a "verdade que está na natureza" e que é nosso papel descobri-la e codificá-la. Essa prática, é fácil perceber, tende a ser pouco relevante para nossas realidades.

A partir daí, como se conforma a Extensão? Nós a definimos em função de uma espécie de consciência pesada. Depois de exercer o direito à "liberdade acadêmica" e o dever auto-imposto de buscar a "qualidade", depois de fazer a pesquisa que nos interessa fazer, só então, marginalmente e no tempo que sobra, "estendemos" seu resultado à sociedade para "retribuir" o que ela gasta para manter a universidade. Esta definição implica que não buscamos saber o que a sociedade nos reclama, nem fazemos o que nos solicitaram, mas que atuamos sobre o que acreditamos que a sociedade necessita. A Extensão não é planejada antecipadamente, não é um ex ante, não se define previamente à realização da pesquisa.

A Extensão aparece em nosso ambiente universitário não faz muito tempo e como algo suplementar à pesquisa e à docência. Até recentemente se acreditava que pelo simples fato de existir uma oferta - um conhecimento "de qualidade" gerado na universidade -, essa oferta encontraria sua demanda. Mas a extensão surge como terceira missão (função) universitária porque o que propõe o modelo ofertista linear não ocorre na realidade. Neste sentido, é interessante assinalar que a ideia de Extensão (similarmente ao que ocorre com o conflito qualidade versus relevância, e pelas mesmas razões) adquire entre nós uma importância muito maior do que a que tem nos países avançados. Algo análogo ocorre em relação à interação universidade-empresa: não há lugar no planeta onde, desde os anos 1950, mais se tenha falado, escrito e tentado fazer através de políticas públicas, do que na América Latina.

\section{Elementos para a concepção de um novo projeto}

Esta seção é dedicada a abordar aspectos que parecem centrais para a concepção de um novo projeto, tendo como referência o que foi tratado na trilogia Ensino, Pesquisa e Extensão. Vou, então, referir-me às considerações feitas na seção anterior, que procuraram ater-se ao plano descritivo-explicativo, para - levando em conta os aspectos que apresenta o contexto socioeconômico da universidade, atinentes a cada uma dessas funções - apresentar o que estou submetendo à consideração para promover o debate. Devido a isso, e pelo anunciado viés normativo desta seção, devemos começar pela Extensão.

Por contraste com a situação atual, tomo como referência um cenário de desenvolvimento inclusivo, socialmente justo, economicamente igualitário e ambientalmente responsável para pensar a função Extensão. A primeira ideia que se depreende do exposto é a inviabilidade do modelo tecnoprodutivo, que é sustentado pelas elites econômicas e penaliza o conjunto da população. A segunda é o considerável desafio associado ao enorme déficit de capacidade material que nossa sociedade apresenta para lidar, por um lado, com suas 
demandas coletivas por infraestrutura, e, por outro, com a exclusão social. A terceira é a possibilidade de que o potencial produtivo e tecnocientífico e a energia gasta até agora para implementar aquele modelo sejam destinados a atender esse desafio.

Como muitas vezes ocorre quando queremos alterar as propriedades de um sistema complexo - e o sistema público de ensino superior e de pesquisa que é o núcleo da sociedade do conhecimento que queremos é inegavelmente deste tipo - cujos componentes interatuam com seu contexto, se co-organizam e conferem uma configuração inconveniente, há que prever dinâmicas de resiliência e histereses. O que implica entender, por um lado, que o caminho para a "volta" para um estado anterior tido como desejável é distinto daquele que lhe deu origem y se quer alterar. E, por outro, que para gerar alterações sistêmicas com sinergia positiva ao interior do sistema, devemos aproveitar as tendências da mudança do contexto que são favoráveis a nosso propósito. Além disso, muito mais importante, privilegiar os canais que conectam o sistema com seu contexto y que podem catalisar movimentos que nos interessam.

\subsection{A Extensão como canal privilegiado para a concepção de um novo modelo e gatilho de transformação}

Para formular um novo projeto para nossa universidade isolada, focalizando os canais que podem nos conectar com nosso contexto, é necessário fazê-lo pelos canais um tanto obstruídos da extensão. E não pela investigação ou pela docência, como propõe o pensamento conservador modernizante. Temos que mudar a maneira com que fazemos extensão para, a partir daí, modificar, possivelmente nesta ordem, a pesquisa e a docência.

Para montar do modo que me convém o quebra-cabeças das três funções da universidade que apresentei, e continuar com meu argumento, peço licença para fazer um jogo de palavras e começar dizendo que não devemos fazer Extensão como temos feito até agora, mas sim "Intenção". "Intenção" no sentido de internalizar a agenda cognitiva dos movimentos sociais, como diretriz de nossa atividade. Ou seja, temos que agir com a intenção clara de conhecer os problemas da sociedade, contribuir para resolvê-los e para que outros, participando deste processo, possam aproveitar o conhecimento gerado. Não através de um enfoque disciplinar e isolado, "em busca da verdade". A universidade se orientaria, então, por uma busca, na realidade que a circunda, dos problemas sociais que precisam ser resolvidos incorporando conhecimento. Intenção significa ter intenção de fazer algo e também internalizar, trazer para dentro da universidade aquela agenda.

Continuando, proponho um neologismo: "exvestigação", que seria construir conhecimento em conjunto com estudantes e movimentos sociais "para fora" e não "para dentro" do mundo da universidade e da ciência como o temos feito até agora. Esse processo seria problem oriented e policy oriented, e não orientado por disciplinas ou simplesmente para conhecer sem nos comprometermos com a mudança. Isto é algo que não estamos costumados a fazer, apesar de existirem propostas e iniciativas importantes no campo da

\begin{tabular}{l|l|l} 
v.2 & n.1 & p.31-50
\end{tabular}


pesquisa participante ou da pesquisa-ação, a universidade é vista por nós (e por isso, pelo conjunto da sociedade) como o reino da verdade e não como território da política (no duplo sentido que tem em nossa língua, de policy e de politics); como se fosse possível fazer conhecimento não politizado. Este é um tema pantanoso. É muito difícil estimar até que ponto a universidade pode politizar-se sem se partidarizar. Mas é ingênuo (ou algo pior) acreditar que ela deve se manter como um espaço quase templário e religioso onde não entram valores morais e interesses econômicos e políticos. A universidade está impregnada por eles e é irreal e nociva a ideia de que, sendo nós animais políticos, a universidade poderia não ser um território de enfrentamento político, de disputa de projetos políticos.

Continuando, proponho outro: mudar docência por "decência". Isso talvez seja algo injusto para muitos de nós. Mas frequentemente, o que encontramos na universidade é o "cumpro-e-minto" e não o cumprimento verdadeiro de nosso papel. É uma docência que muitas vezes não é compatível com a decência. E somente des-sacralizando e politizando a docência, encontraremos motivação suficiente para contribuir a construir uma sociedade decente. De fato, muito do que ensinamos na universidade é um conhecimento que não serve mais, se é que alguma vez serviu, para melhorar a sociedade que nos mantém. Com muito pouco de análise crítica e também de autocrítica nos daríamos conta de que nossa docência reproduz um passado injusto e não aponta para o futuro que a sociedade deseja. Enquanto isso, aprisionados na armadilha que nós mesmos fabricamos, seguimos "cumprindo" formalmente o que arbitramos que deve ser nosso papel e "mentindo". Não estamos quebrando nenhuma norma, nenhuma lei, mas estamos mentindo para a sociedade e para nós mesmos.

\subsection{A Economia Solidária e a Tecnologia Social como fatos portadores de futuro}

Voltando ao que o pensamento sistêmico pode contribuir para nossa análise, depois de focalizar o canal que poderia reconectar-nos de modo virtuoso com nosso contexto, destaco as tendências de mudanças socioeconômicas que são favoráveis ao meu argumento. Utilizando a gíria da Prospectiva ou dos Estudos de Construção de Futuro, ressalto que a dupla Economia Solidária - Tecnologia Social deve ser interpretada como um fator portador de futuro e que configura uma tendência de peso.

O núcleo de meu argumento é a constatação de que o crescimento da demanda tecnocientífica real e, principalmente, potencial dos empreendimentos da Economia Solidária (ES) que vêm surgindo no processo de precarização do mundo do trabalho, da desindustrialização e da informalização que afeta a milhões de brasileiros representa, apesar de socialmente dramática para o país, uma oportunidade para a universidade.

A proposta da ES, que vem ocupando um espaço crescente na agenda de atores sociais que a encaram a partir de perspectivas que abrangem desde a filantropia, passando pela "responsabilidade social empresarial" ou a eclesiástica, até à da construção do socialismo, não é nova. Seu (re)surgimento no Brasil - e em outros países da América Latina - se deve

\begin{tabular}{l|l|l|l|l|l|l} 
(C) Rev. Inter. Educ. Sup. & Campinas, SP & v.2 & n.1 & p.31-50 & jan./abr. 2016 & ISSN 2446-9424
\end{tabular}


ao processo de crescente exclusão da Economia Formal que afeta à classe trabalhadora.

Seu propósito é o fortalecimento de um arranjo societário baseado na organização do movimento social que está emergindo da Economia Informal. A ES agrupa empreendimentos solidários baseados, ao contrário das empresas privadas e estatais, na propriedade coletiva dos meios de produção, na qual trabalhadores associados se dedicam à produção de bens e serviços de modo auto-gestionário e desconcentrado. Mesmo quando ainda submetidos à dinâmica do "mercado", comprando ou vendendo para a Economia Formal, eles tendem a formar cadeias produtivas cada vez mais densas, completas e entrelaçadas e crescentemente autônomas.

Demandam um decidido apoio governamental e, na medida em que recebem benefícios, qualitativamente semelhantes e quantitativamente proporcionais aos que hoje recebem as empresas, eles poderão funcionar como "porta de saída" para os programas compensatórios atualmente existentes. Interessa destacar o apoio que devem receber para sua capacitação naquelas habilidades e competências que necessitam para se tornarem sustentáveis.

À medida que se consolidem, os empreendimentos solidários irão desenvolvendo, mediante a Adequação Sociotécnica ${ }^{5}$ da tecnociência convencional produzida para e pelas empresas, e com o esperado apoio do complexo público de ensino e pesquisa, a Tecnologia Social (TS) que os tornará - econômica, social, cultural e ambientalmente - crescentemente sustentáveis.

\subsection{Iniciativas incipientes na universidade}

Em função do grau de maturidade alcançado pelo movimento da ES e da TS, começa a se propagar entre segmentos da burocracia e da comunidade universitária a percepção de que a sustentabilidade destes empreendimentos, o fortalecimento de sua posição relativa perante o mercado formal e o combate à exclusão social dependem de alternativas tecnocientíficas adequadas. Um conhecimento coerente com um enfoque que rejeita, por ser capaz de entender suas raízes ideológicas, expressões como "alta tecnologia" (como se houvesse uma tecnologia "baixa"!) ou "tecnologia de ponta" (como se houvesse uma "arredondada"!). Um enfoque que explicita o fato de que, independentemente da intensidade de conhecimento novo ou a ser desenvolvido, a tecnociência das empresas, por ser socialmente construída para atender os valores e interesses da classe proprietária, é adequada para atendê-los.

Provavelmente porque o objetivo mais abrangente e de mais longo prazo deste

\footnotetext{
5 A Adequação Sociotécnica pode ser entendida como um procedimento que busca adequar o conhecimento tecnocientífico convencional (produzido por e para as empresas privadas), a processos de produção e circulação de bens e serviços, de forma coerente com os interesses de grupos sociais relevantes distintos daqueles que os originaram organizados em empreendimentos solidários.
}

\begin{tabular}{l|l|l|l|l|l|l} 
(C) Rev. Inter. Educ. Sup. & Campinas, SP & v.2 & n.1 & p.31-50 & jan./abr. 2016 & ISSN 2446-9424
\end{tabular}


enfoque é a criação da plataforma cognitiva (TS) e civilizacional (ES) que levaria à construção de uma sociedade diferente da atual, baseada em valores coerentes com a justiça social, a igualdade econômica e a responsabilidade ambiental e, por isso, mais adequada à realização das potencialidades humanas, ele despertou o interesse do segmento de esquerda de professores, pesquisadores e estudantes. De fato, uma das iniciativas mais importantes - e inovadoras a nível mundial - que vem sendo implementada na América Latina no campo da Extensão universitária é a das incubadoras (tecnológicas) de cooperativas (populares) em universidades (em sua maioria, públicas) brasileiras.

Esse segmento mais radical sustenta que, além de libertária em termos ideológicos e culturais, nossa educação somente será efetiva se formar a população para que se organize em empreendimentos solidários com propriedade coletiva dos meios de produção e com TS autogestionária, capazes de substituir a empresa privada, realimentando a cadeia virtuosa de políticas públicas de novo tipo.

Por outro lado, é necessário sugerir a preocupação acerca da formação que recebem os estudantes; mais especificamente, sobre o conteúdo que é oferecido em carreiras como as de Engenharia, "ciências duras" e Administração. Até agora orientados à formação de estudantes habilitados para atuar em empresas privadas e para desenvolver conhecimento tecnocientífico a elas funcional, referidos conteúdos não se mostram adequados para capacitar profissionais aptos para trabalhar em situações como as que tendem a surgir nos contextos da ES e para um cenário produtivo nacional e um contexto econômico internacional diferentes.

Quando se pede a um engenheiro de esquerda que projete uma tecnologia, ele vai fazê-lo com as ferramentas que conhece e de acordo com o marco analítico-conceitual de que dispõe. Se ele não souber como introduzir em sua "planilha de cálculo", aquela com a qual está acostumado a trabalhar, os parâmetros técnicos e econômicos associados ao "custo" da exploração dos operários, da degradação ambiental, da obsolescência programada, etc., não conseguirá atender o pedido. Por mais simples que possa ser a proposta da ES e disposto que esteja a enquadrar-se nela.

Trata-se de desconstruir o marco analítico-conceitual "herdado" e reconstruir outro novo, que permita a consideração dos valores e interesses que conformam um novo estilo de desenvolvimento. Essas duas operações - de desconstrução e reconstrução - não devem ser encaradas como estágios diacrônicos, auto-conteúdos e sucessivos. Elas se darão mediante uma sucessão de momentos iterativos, interativos, interpenetrados e realimentados realizados de modo a provocar a transformação do marco analítico-conceitual. Conceitos, critérios, relações, modelos, feitos estilizados, algoritmos, variáveis e parâmetros terão que ser especialmente concebidos para ir mudando a "planilha de cálculo" dos profissionais, tornando-a flexível e permeável a outras formas de conhecer e aos atores sociais que defendem os valores e interesses com os quais se identificam. Em outras palavras, a concepção de um marco analítico-conceitual capaz de orientar as ações dos profissionais interessados na adoção de um estilo alternativo de desenvolvimento. 
Acoplada a essa percepção, está a expectativa de que os programas compensatórios que hoje abarcam um terço da população latino-americana possam proporcionar a seus beneficiários condiciones para a geração de oportunidades de trabalho que possibilitem um crescente empoderamento e autonomia frente ao circuito da economia formal mediante tecnologias que possibilitem a completitude e o fortalecimento das cadeias produtivas da ES.

\section{O novo projeto e as demandas socioeconômicas e cognitivas emergentes}

Uma derivação do argumento que venho expondo é a pergunta de porquê continuar emulando um padrão de tecnociência que não é neutro, que serve às grandes potências e está cada vez mais monopolizado por suas grandes empresas.

No Brasil, como no resto da América Latina, há uma grande necessidade de satisfazer demandas materiais de bens e serviços relacionados com energia, transporte, moradia, alimentação, saúde, educação, comunicações, etc. Entretanto, se observamos a orientação que teve a exploração da fronteira tecnocientífica, pode-se ver que existe um déficit cognitivo envolto na produção desses bens e serviços que o processo de democratização econômica exigirá. O "progresso tecnológico" se orientou, como é natural que assim ocorra em sociedades capitalistas, para atender à demanda pujante dos ricos dos países ricos. Não se desenvolveu conhecimento eficaz para o que necessitam os pobres dos países pobres. Assim, a tecnologia relacionada com infraestrutura e produção de bens e serviços públicos costuma ser ineficiente e ambientalmente desastrosa.

Não obstante, a maior parte dos professores universitários e pesquisadores costuma dizer que os problemas associados à satisfação das necessidades básicas são meramente políticos. Que não são tecnológicos e muito menos científicos. A Argentina, por exemplo, que produz comida para 700 milhões de pessoas, tem 40 milhões de habitantes e 20 milhões chegaram há algum tempo a passar fome. Existe tecnologia para produzir comida para todos os argentinos? Eu tenho certeza que não. Porque se a tecnologia disponível foi projetada para produzir de forma concentrada em termos de escala e de propriedade dos meios de produção, o produto gerado vai estar concentrado; e será necessário gastar muita energia, inclusive política, que costuma ser a mais escassa, para reparti-lo de acordo com critérios socialmente aceitáveis. Em consequência, enquanto não desenvolvamos formas de produzir (ou tecnologias) adequadas à propriedade coletiva dos meios de produção, à autogestão, etc., é altamente improvável que as necessidades das maiorias possam ser satisfeitas de maneira aceitável. O que mostra que os problemas associados à satisfação das necessidades básicas não são meramente políticos, mas também tecnocientíficos.

Outro exemplo: no Brasil vamos ter que acelerar a reforma agrária. Como faremos isso? Dividiremos a terra? Daremos a cada agricultor uma pá, um enxadão e um saco de sementes? Óbvio que não. Isso seria condenar a experiência ao fracasso. Obviamente, se 
necessita um padrão tecnocientífico diferente que permita ao pequeno produtor ser, se não "competitivo", sustentável. E esse pacote tecnológico não é da Monsanto, que é insustentável desde o ponto de vista ambiental e inacessível para o pequeno produtor.

Mais um exemplo: quase a metade das casas brasileiras não tem água potável. Como se resolve isto? Basta conectar todas as casas a uma rede com tubos de plástico baratos para que qualquer família pobre possa comprá-los? Novamente devo dizer que não. Estamos falando de milhões e milhões de casas. Por isso estamos obrigados a resolver primeiro outros temas, como: de onde tirar a água? Como transportá-la? Como purificá-la? Como distribuíla? Como assegurar que haja água para todos? Como fazer com que a água utilizada seja tratada?

Todos estes são problemas que têm um componente tecnocientífico, o que não exige somente que façamos muita pesquisa. É necessário que seja realizada de uma forma bem diferente da atual. Há que reconhecer que a pesquisa interdisciplinar, aquela que trabalha por problema e não por disciplina, não é a que aprendemos, sabemos e ensinamos a fazer. Ela não se faz em lugar nenhum.

\section{Considerações finais}

A dificuldade de incorporar as demandas cognitivas da democratização à agenda universitária pela via da Extensão possui evidentes desdobramentos para o projeto que devemos conceber. Como tentam fazer os países avançados, ainda submersos no pântano do neoliberalismo ao clamar por uma sociedade do conhecimento, nós temos que conceber nossa sociedade do conhecimento. A sociedade que temos que ajudar a construir terá que ser intensiva em conhecimento. Mas, seguramente, não do mesmo conhecimento que os grandes conglomerados produzem e que está levando a uma crescente inequidade e insustentabilidade.

Para isso, cada vez mais temos que pensar as áreas das políticas públicas que se relacionam mais diretamente com o conhecimento como germens de uma futura política cognitiva que orientará nosso caminho na direção de uma sociedade na qual o conhecimento seja de todos e para todos, compartilhado e produzido por todos.

A disfuncionalidade vai continuar enquanto a comunidade universitária se mantiver refratária e não escutar os sinais de relevância que os movimentos sociais estão emitindo cada vez com maior intensidade e frequência. Mas se ela se convencer de que a tecnociência pode ser redesenhada, haverá uma chance de que a universidade tenha um futuro brilhante, que vai além de proporcionar uma "educação de qualidade", permitir a um número crescente de jovens uma posição no mercado formal de trabalho. 
As dificuldades são muitas. Tentativas de reorientar a agenda de pesquisa tendem a ser vistas pelos mais conservadores como uma intervenção perniciosa, ainda que esteja cada vez mais claro que ela é um ente que somente se manifesta a posteriori, que seus temas são escolhidos de forma pouco racional, atomizada e sem participação. A política científica e tecnológica segue sendo controlada predominantemente pelo alto clero da ciência dura e não tem havido possibilidade de trazer novos atores para participar de sua elaboração. Essa situação leva a um círculo vicioso, que se agrava pelo caráter de arquipélagos que são nossas universidades e pela incompreensão e a dificuldade de diálogo entre "inexatos" e "desumanos".

As discussões políticas (de policy e de politics) com caráter estratégico (que pesquisa faremos?; que alunos queremos formar?; qual é o papel da universidade?, etc.) não ocorrem com frequência nos órgãos de direção da universidade, nos conselhos, nas reuniões de departamento. Quando esses temas aparecem, o fazem em congressos de educadores onde os gestores não participam. Ainda não conseguimos que essas discussões penetrem nos organismos políticos. Praticamente não existe uma discussão policy oriented que possa reorientar as práticas do ensino, pesquisa e extensão. Entretanto, que possibilidade temos de mudar a gestão da universidade a não ser politizando, no bom sentido do termo, a vida universitária? Somente à medida que essa politização ganhar corpo, conseguiremos modificar a realidade de nossa universidade e de sua relação com a sociedade.

Assim, em uma sociedade na qual não emergiu o que Amílcar Herrera chamava de "projeto nacional" intensivo em conhecimento localmente produzido, onde é muito escassa a demanda por "pessoal bem formado" para as empresas e na qual, além disso, o critério que se usa para conformar a agenda de pesquisa e ensino és exógena e incoerente, já que se baseia na "qualidade" (e por isso, na relevância dos países avançados), é claro que há uma enorme necessidade de refazer os critérios de avaliação que orientam o comportamento da comunidade de pesquisa e produzir uma nova agenda de pesquisa. A questão é saber como fazê-lo quando "a Capes e o $\mathrm{CNPq}^{6}$ não o permitem". A primeira que temos que reconhecer é que essas instituições são e sempre foram nossas. É a comunidade de pesquisa, hegemônica na elaboração da política de C\&T e de ensino superior, que decide o que ela faz. E se ela continua fazendo o que cada vez mais colegas condenam "nos corredores" é porque os que não estão de acordo com essa orientação não conseguiram disputar a hegemonia no âmbito da universidade, que é onde se forma o ethos que orienta esse comportamento. Isto significa, por último, que discussões como a que aqui se está propondo sejam realizadas nos conselhos, reuniões de departamento, laboratórios e salas de aula de nossa universidade. Não me parece que haja outra saída.

\footnotetext{
${ }^{6}$ A Coordenação de Aperfeiçoamento de Pessoal de Nível Superior (Capes), uma fundação do Ministério da Educação do Brasil e o Conselho Nacional de Desenvolvimento Científico e Tecnológico (CNPq), uma agência do Ministério da Ciência, Tecnologia e Inovação, se dedicam centralmente ao fomento da formação de pósgraduação e à promoção da pesquisa científica, respectivamente.
}

\begin{tabular}{l|l|l|l|l|l|l} 
() Rev. Inter. Educ. Sup. & Campinas, SP & v.2 & n.1 & p.31-50 & jan./abr. 2016 & ISSN 2446-9424 \\
\hline
\end{tabular}

